\title{
ANÁLISE DA ARBORIZAÇÃO URBANA EM BAIRROS DA CIDADE DE POMBAL NO ESTADO DA PARAÍBA
}

\author{
Francisco Rodolfo Júnior ${ }^{1}$, Rafael Rodolfo de Melo $^{2}$, Thiago Augusto da Cunha ${ }^{2}$, \\ Diego Martins Stangerlin ${ }^{2}$
}

(recebido em 03.03.2008 e aceito para publicação em 16.10.2008)

\begin{abstract}
RESUMO
O presente trabalho teve como objetivo a análise da arborização urbana em três bairros da cidade de Pombal, no Estado da Paraíba. Para isso, foram realizados inventários totais (censo) em quatro ruas de cada bairro que foram escolhidas aleatoriamente. Os dados foram coletados em um formulário padronizado, que continham informações sobre data de coleta, rua, bairro, nome vulgar das espécies, fase de desenvolvimento, fitossanidade, problemas com a raiz, necessidade de poda, afastamento predial, altura total, altura da primeira bifurcação, diâmetro e situação das copas. Ao total foram amostradas 212 árvores, sendo 49\% destas no bairro Santo Antônio. Ficus benjamina L. foi à espécie predominante, representada por $51 \%$ das árvores amostradas. O bairro Jardim Rogério obteve o maior número de resultados indesejáveis para a arborização dentre os parâmetros avaliados.
\end{abstract}

Palavras-chaves: Arborização urbana, diagnóstico, Pombal.

\footnotetext{
${ }^{1}$ Professor Substituto, M.Sc., Universidade Federal de Campina Grande, Centro de Ciências e Tecnologia Agroalimentar, Campus de Pombal, Endereço: Rua Coronel João Leite, n 517 - Centro, Pombal-PB - CEP: 58.840-000, Doutorando pela Universidade Federal Rural de Pernambuco, Programa de Pós-Graduação em Ciência do Solo, Recife, PE <fcorodolfojunior@hotmail.com>;

2 Engenheiros Florestais, Mestrandos pela Universidade Federal de Santa Maria, Centro de Ciências Rurais, Programa de Pós-Graduação em Engenharia Florestal, Santa Maria, RS <rrmelo2@yahoo.com.br>;
} 


\title{
URBAN ARBORIZATION ANALYSIS IN POMBAL, PARAÍBA STATE, BRAZIL
}

\begin{abstract}
This study has objective the urban forest analysis in three neighborhood in Pombal, Paraíba State, Brazil. Were realized census in four streets of each quarter had been carried through that had been chosen randomly. The data had been collected in a standardized form, that contained information on date of collection, street, quarter, name of the species, phase of development, health, root problems, necessity of pruning, land removal, total height, height of the first bifurcation, diameter and situation of the pantries. To the total they had been showed to 212 trees, being $49 \%$ of these in the Santo Antonio quarter. Ficus Benjamina L. it was to the predominant species, represented for $51 \%$ of the showed trees. The quarter Jardim Rogério got the biggest undesirable number of results for the arborization amongst the evaluated parameters.
\end{abstract}

Key-word: Urban arborization, diagnosis, Pombal. 


\section{INTRODUÇÃO}

Entende-se por arborização urbana, o conjunto de terras públicas e privadas, com vegetação predominantemente arbórea que uma cidade apresenta, ou ainda, é um conjunto de vegetação arbórea natural ou cultivada que uma cidade apresenta em áreas particulares, praças, parques e vias públicas (SANCHOTENE, 1994; SILVA JÚNIOR e MÔNICO, 1994). Para Gonçalves (2000), atualmente o conceito de arborização urbana tem dado lugar a um conceito mais abrangente e a nova área do saber denominada "silvicultura urbana", por se entender que os agrupamentos de árvores são mais significativos que árvores isoladas.

A vegetação urbana desempenha funções essenciais nos centros urbanos. Do ponto de vista fisiológico, melhora o ambiente urbano por meio da capacidade de produzir sombra; filtrar ruídos, amenizando a poluição sonora; melhorar a qualidade do ar, aumentando o teor de oxigênio e de umidade, e absorvendo o gás carbônico; amenizar a temperatura, entre outros aspectos (GRAZIANO, 1994). Segundo Volpe-Filik et al. (2007), as árvores desempenham um papel vital para o bem-estar das comunidades urbanas; sua capacidade única em controlarem muitos dos efeitos adversos do meio urbano deve contribuir para uma significativa melhoria da qualidade de vida, exigindo uma crescente necessidade por áreas verdes urbanas a serem manejadas em prol de toda a comunidade.

No Brasil, salvo raras exceções, a arborização urbana não passa por um planejamento prévio, embora essa mentalidade esteja aos poucos se modificando (SILVA et al., 2006). Para Milano (1994), a arborização urbana no Brasil é uma atividade relativamente nova e tem sido realizada com raras exceções, sem planejamento. Neste contexto, a arborização de ruas requer para a efetivação dos benefícios esperados, que seja adequadamente planejada e mantida de forma sustentável. O mesmo autor em um trabalho relata que os inventários para avaliação da arborização de ruas podem ser de caráter quantitativo, qualitativo ou quali-quantitativo.

Para se conhecer a arborização urbana, é necessária a sua avaliação, o que depende da realização de inventário. O inventário da arborização tem como objetivo geral conhecer o patrimônio arbustivo e arbóreo de uma localidade. Tal levantamento é fundamental para o planejamento e manejo da arborização, fornecendo informações sobre a necessidade de poda, tratamentos fitossanitários ou remoção e plantios, bem como para definir prioridades de intervenções (MELO et al., 2007).

Por meio de um inventário é possível verificar os erros e acertos na arborização de uma cidade. A importância do inventário está no fato de que através dele pode-se conhecer o patrimônio arbóreo e identificar as necessidades de manejo. Um dos aspectos mais 
importantes do inventário é quando este é realizado de forma a fornecer uma contínua atualização das informações (TAKAHASHI, 1994).

O inventário, dada a sua grande abrangência, pode funcionar como um poderoso instrumento de esclarecimento e persuasão dos administradores e usuários do local inventariado (MILLER, 1997). Tão importante como definir a abrangência do inventário, é a definição da metodologia a ser aplicada na coleta dos parâmetros, enfatizando a sua intensidade, ou seja, se estes serão medidos integralmente, ou parcialmente, e se serão agrupados em classes de valores ou preservados os valores originais. As informações a serem coletadas dependem basicamente dos objetivos do inventário e da disponibilidade de recursos (SILVA, et al., 2006). Quanto maior o número de informações desejadas, maior a complexidade do inventário, e conseqüentemente maiores serão os seus custos.

As características e parâmetros a serem avaliados devem abordar alguns pontos básicos, como a localização da árvore (rua, bairro, número da casa), características da árvore (espécie, porte, fitossanidade) e características do meio (largura de ruas e passeios, espaçamento do plantio, pavimentação dos passeios, presença de redes de serviços, afastamento predial, tipo de forração na área de crescimento) (SILVA, et al., 2006).

O presente trabalho teve como objetivo analisar a arborização urbana nos bairros Jardim Rogério, Santo Antônio e Santa Rosa, localizados no município de Pombal, Estado da Paraíba.

\section{MATERIAIS E MÉTODOS}

\section{Área de Estudo}

O estudo foi realizado em três bairros na cidade de Pombal. Os bairros inventariados foram Jardim Rogério, Santo Antônio e Santa Rosa. A cidade de Pombal está situada na região semi-árida do Nordeste brasileiro, no Estado da Paraíba a cerca de $371 \mathrm{~km} \mathrm{da}$ capital, João Pessoa (Figura 1). Encontra-se a aproximadamente $184 \mathrm{~m}$ de altitude média do mar, com as coordenadas $06^{\circ} 46^{\prime} 12^{\prime \prime}$ S e $37^{\circ} 48^{\prime} 07^{\prime \prime} \mathrm{W}$. Sua população é representada por pouco mais de 33.000 habitantes, que ocupam uma área de $889 \mathrm{~km}^{2}$, perfazendo uma densidade de 37,4 habitantes $/ \mathrm{km}^{2}$ (IBGE, 2008).

O município está inserido na unidade geoambiental da depressão sertaneja, que representa a paisagem típica do semi-árido nordestino. A vegetação é basicamente composta por caatinga hiperxerófila com trechos de floresta caducifólia. O clima é do tipo tropical semi-árido, com chuvas de verão (MME, 2005). A temperatura média anual é de $27^{\circ} \mathrm{C}$, com médias mensais variando pouco entre si. A pluviosidade média anual é de 
aproximadamente $800 \mathrm{~mm}$, sendo irregularmente distribuída entre os meses, com maior incidência entre os meses de fevereiro a abril, mas, com grandes variações de ano para ano (PARAÍBA, 1985).

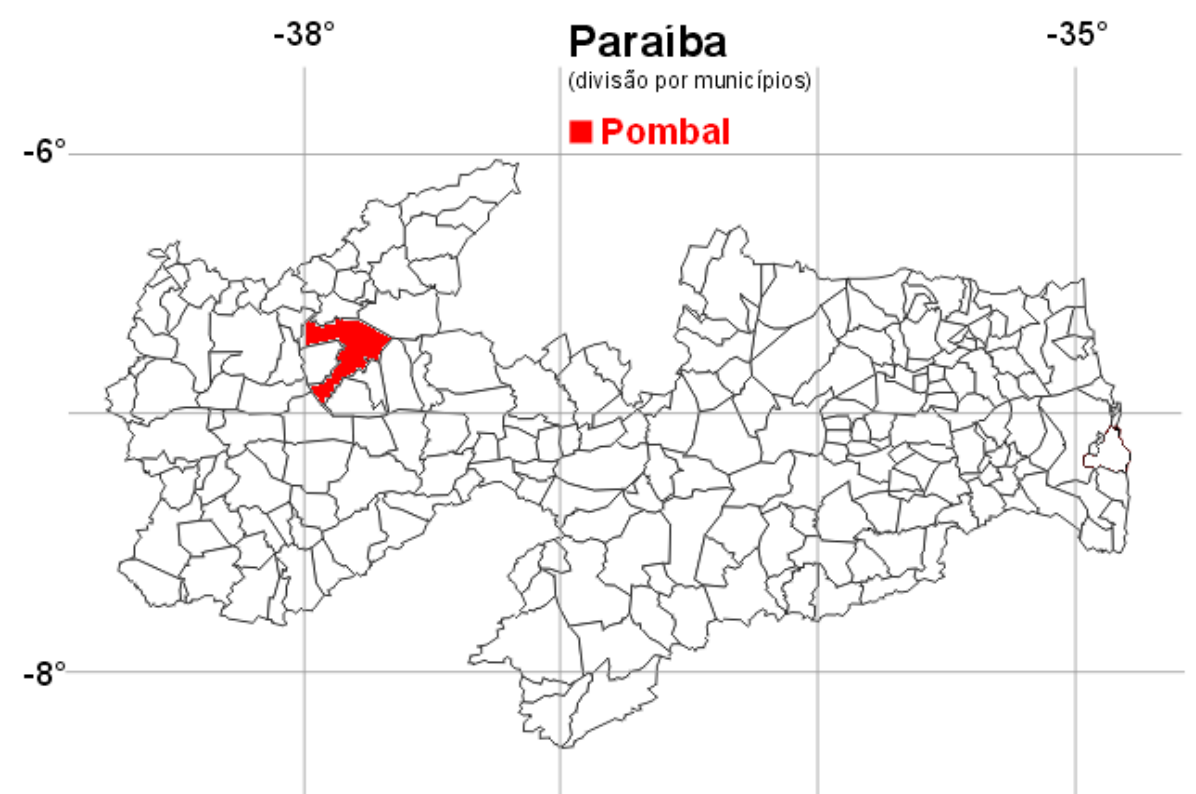

Figura 1. Localização da cidade de Pombal no Estado da Paraíba (IBGE, 2008).

\section{Inventário}

O método de inventário utilizado no levantamento foi em forma de amostragem. Para isso, foram sorteadas aleatoriamente cinco ruas por cada bairro (Tabela 1). Para cada uma delas foi realizado o censo, também denominado inventário total, onde foram coletados dados de caráter quali-quantitativo.

Tabela 1. Ruas sorteadas para cada bairro, onde foram realizados o inventário.

\begin{tabular}{cl}
\hline Bairro & \multicolumn{1}{c}{ Ruas } \\
\hline & - Cabo João Monteiro da Rocha \\
Jardim Rogério & - Nilton Seixas \\
& - Odilon Lopes \\
& - Professor Luis Ferreira Campos \\
\hline \multirow{3}{*}{ Santo Antônio } & - Candido de Assis \\
& - Joaquim Ferreira de Lima \\
& - João Josias de Sousa \\
& - Manoel Bezerra de Sousa \\
\hline \multirow{3}{*}{ Santa Rosa } & - Pedro Junqueira \\
& - José Tavares de Araújo \\
& - Francisco da Silva Pereira \\
& - Dorgival da Costa Romeu \\
\hline
\end{tabular}


Os dados foram coletados em formulário específico (MELO et al., 2007), com informações sobre a data de coleta, rua, bairro, setor e o número de quadras sorteadas. Quanto às informações sobre as árvores, foram coletados o nome vulgar, fase de desenvolvimento, fitossanidade, problemas com a raiz, necessidade de poda, afastamento predial, altura total, altura da primeira bifurcação, diâmetro e situação das copas (Figura 2). 


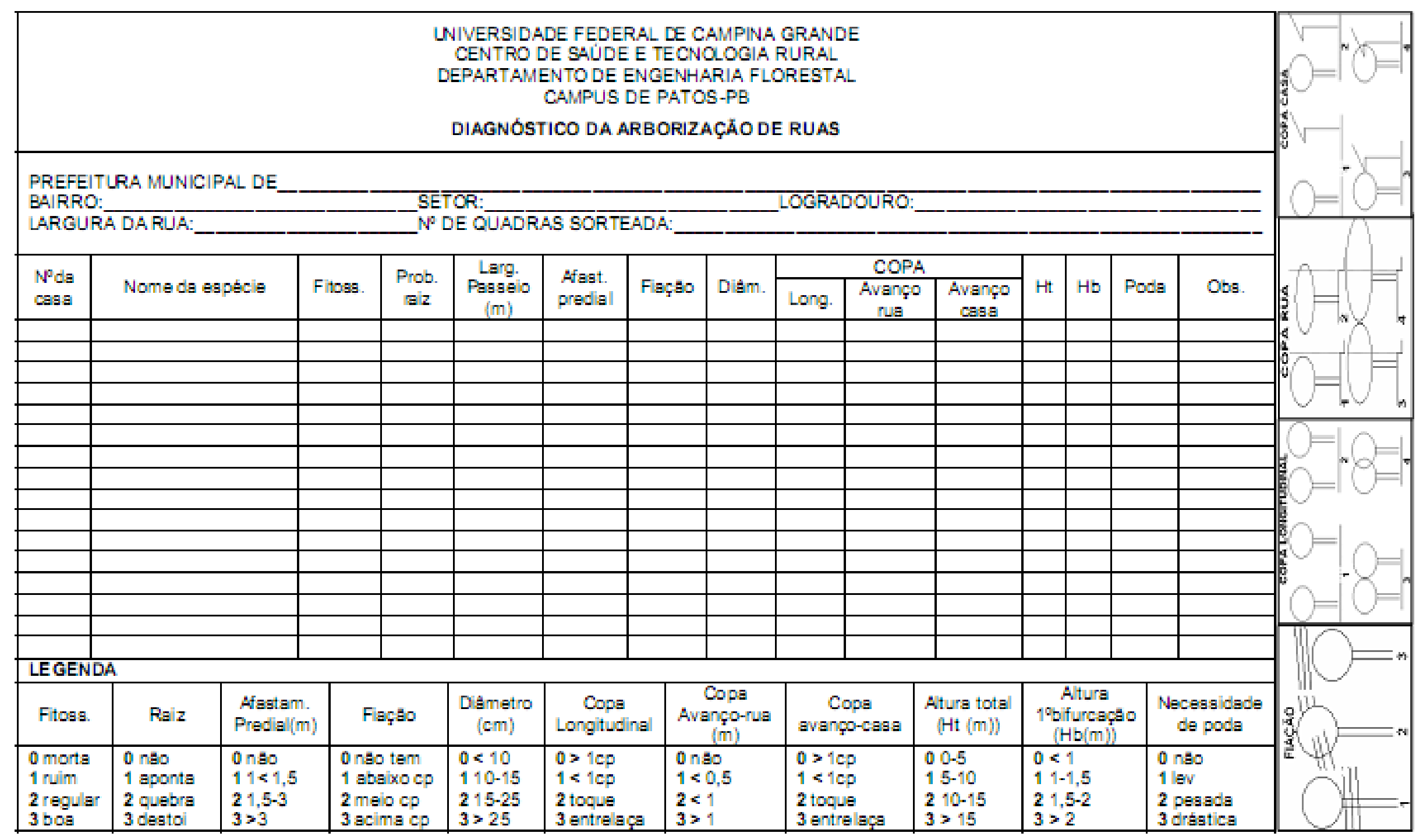

Figura 2. Formulário utilizado para a coleta de dados da arborização urbana, na cidade de Pombal, PB (MELO et al., 2007). 


\section{Avaliações}

A diversidade de espécies foi avaliada, assim como seu desenvolvimento, sendo classificadas como jovens ou adultas. Com base nos dados, pode-se avaliar a homogeneidade da arborização do bairro.

As condições da sanidade das árvores foram analisadas conforme as seguintes categorias: morta - apresenta danos irreversíveis de pragas, doenças ou graves danos físicos; ruim - apresenta estado geral de declínio que podem ser severos danos de pragas, doenças ou defeitos físicos e, não aparentando morte iminente, podendo requerer muito trabalho e tempo para a recuperação; regular - apresenta condições e vigor médios, mostrando sinais de pragas doenças ou danos físicos, necessitando de poda corretiva, reparo de danos físicos ou controle sanitário; boa - vigorosas e que não apresenta sinais de pragas doenças ou injurias mecânicas.

Com relação aos problemas da raiz em condições externas, as espécies foram codificas em quatro categorias, foram elas: nenhum - raiz não se encontra exposta; aponta - raiz está apontando na superfície do solo; quebra - a raiz se expõe na superfície e apresenta sinais de quebra no passeio ou na rua; destrói - ao emergir na superfície quebra a estrutura superficial.

De acordo com a necessidade de podas, levaram-se em considerações os seguintes aspectos: nenhuma - não há necessidade de poda no momento atual; leve - árvore necessita de uma poda leve para manutenção; pesada - necessidade de poda pesada; drástica - em virtude de danos ou outros problemas apresentados necessita de uma poda drástica.

Procurou-se também, diagnosticar a situação das copas das árvores a partir dos seguintes parâmetros: copa longitudinal - permite-se averiguar se o espaçamento utilizado no plantio foi adequado; avanço na rua - possibilidade de causar sérios problemas para o tráfego local; avanço para o prédio - geração de problemas para os moradores da cidade, que vão desde a falta de segurança até a diminuição da iluminação natural.

Também foram avaliados o afastamento predial, parâmetro que diz respeito ao distanciamento entre a árvore e a construção dentro do lote, sobretudo na posição frontal. $\mathrm{Na}$ avaliação da arborização urbana a posição frontal da construção predial tem grande influência na escolha das espécies a serem plantadas. O tamanho das árvores, foi obtido por meio de vara graduada, com precisão de $0,5 \mathrm{~m}$. Já com relação à primeira bifurcação, foi utilizada uma fita métrica para medição do solo até este ponto. 


\section{RESULTADOS E DISCUSSÃO}

$\mathrm{Na}$ análise da Tabela 2, pode ser observado que em média os bairros apresentaram larguras médias das ruas de 9,55 m, e dos passeios de 1,93 m. A ruas e os passeios mais largos foram observados no bairro Jardim Rogério, com 12,65 m e 2,51 m, respectivamente. Já as de menores dimensões, foram observadas no bairro Santa Rosa (7,87 e 1,39 m). De acordo com o manual de arborização publicado pela CEMIG (2001), ruas com larguras superiores a 7,00 m e passeios superiores a 2,00 m, são considerados ideais. Deste modo, nota-se que todas as ruas são consideradas de ruas largas, e entre os passeios, apenas o bairro Jardim Rogério enquadram-se acima do valor proposto.

Tabela 2. Largura média das ruas e passeios, e número de árvores amostradas por bairro.

\begin{tabular}{lcccc}
\hline Bairro & $\begin{array}{c}\text { Largura da } \\
\text { Rua }(\mathbf{m})\end{array}$ & $\begin{array}{c}\text { Largura do } \\
\text { Passeio }(\mathbf{m})\end{array}$ & $\begin{array}{c}\text { Ocorrência } \\
\left(\mathbf{n}^{\mathbf{0}} \text { de árvores) }\right.\end{array}$ & $\begin{array}{c}\text { Ocorrência } \\
(\%)\end{array}$ \\
\hline Jardim Rogério & 12,65 & 2,51 & 64 & 30,19 \\
Santo Antônio & 8,12 & 1,88 & 104 & 49,06 \\
Santa Rosa & 7,87 & 1,39 & 44 & 20,75 \\
\hline Média & $\mathbf{9 , 5 5}$ & $\mathbf{1 , 9 3}$ & $\mathbf{7 0 , 6 7}$ & - \\
\hline Total & - & - & $\mathbf{2 1 2}$ & $\mathbf{1 0 0 , 0 0}$ \\
\hline
\end{tabular}

Houve grande diferença quanto à ocorrência de árvores dentre os bairros, sendo o Santo Antônio o que obteve a maior quantidade de indivíduos amostrados, com 49,06\% do total observado, seguido pelo Jardim Rogério, com 30,19\% e finalmente Santa Rosa, com 20,75\% (Tabela 2).

Em um total de 212 árvores amostradas foram observadas apenas oito espécies, sendo apenas uma dessas, o Ficus benjamina, responsável por aproximadamente $51 \%$ de todos os indivíduos. Dividindo por bairros, o número de espécies fica ainda menor, com cinco, seis e quatro espécies, para os bairros Jardim Rogério, Santo Antônio e Santa Rosa respectivamente, o que reflete a baixa diversidade existente nos bairros. Outro grave problema é a prevalência de uma única espécie (Ficus benjamina), que apresentou percentuais que variam de 57 e $41 \%$ entre os bairros. Entretanto, em estudos recentes, Melo et al. (2007) observaram em um bairro na cidade de Patos-PB, prevalência ainda maior desta espécie, com percentual de aproximadamente 70\% dos indivíduos avaliados.

Alguns autores, dentre eles Grey e Deneke (1986) e Milano e Dalcin (2000), afirmam que cada espécie não deve ultrapassar $15 \%$ do total de indivíduos da população arbórea, para um bom planejamento da arborização urbana. Dentro desse aspecto, o Ficus Benjamina foi à espécie predominante, fugindo às recomendações desses autores. A predominância de apenas uma espécie ou grupo de espécies pode facilitar a propagação das pragas, atualmente muito comum nas árvores em ambiente urbano. 
Tabela 3. Espécies ocorrentes nos bairros inventariados, com seus respectivos nomes científicos, e número de indivíduos amostrados por bairros.

\begin{tabular}{|c|c|c|c|c|c|c|c|c|}
\hline \multirow{2}{*}{ Espécie } & \multirow{2}{*}{ Nome Científico } & \multicolumn{3}{|c|}{ Jd. Rogério Sto. Antônio } & \multicolumn{2}{|c|}{ Sta. Rosa } & \multicolumn{2}{|c|}{ Total } \\
\hline & & $\left(n^{0}\right) \quad(\%)$ & $\left(n^{0}\right)$ & $(\%)$ & $\left(\mathrm{n}^{\circ}\right)$ & $(\%)$ & $\left(\mathrm{n}^{\circ}\right)$ & $(\%)$ \\
\hline Acássia & Cassia ferruginea Schrad. ex DC. & 23,13 & 7 & 6,73 & 0 & 0,00 & 9 & 4,25 \\
\hline roba & Prosopis juliflora (Sw.) DC. & 1218,75 & 0 & 0,00 & 2 & 4,55 & 14 & 6,60 \\
\hline Cássia & Cassia seamea L. & 1828,13 & 23 & 22,12 & 14 & 31,82 & 55 & 25,94 \\
\hline Castanhola & Terminalia catappa L. & $0 \quad 0,00$ & 8 & 7,69 & 0 & 0,00 & 8 & 3,77 \\
\hline Esponja & Acacia farnesiana (L.) Willd. & $0 \quad 0,00$ & 2 & 1,92 & 0 & 0,00 & 2 & 0,94 \\
\hline Fícus & Ficus benjamina $L$ & 3046,88 & 60 & 57,69 & 18 & 40,91 & 108 & 50,94 \\
\hline Linhaça & Linum usitatissimum $L$. & 23,13 & 0 & 0,00 & 10 & 22,73 & 12 & 5,66 \\
\hline Nim indiano & Azadirachta Indica A. Juss & $0 \quad 0,00$ & 4 & 3,85 & 0 & 0,00 & 4 & 1,89 \\
\hline Total & 8 espécies & 64100 & 104 & 100 & 44 & 100 & 212 & 100 \\
\hline
\end{tabular}

Silva (2000) relata que é comum na arborização urbana, que poucas espécies representem a maior parte da população, mesmo não sendo uma situação desejável, quer por razões estéticas ou fitossanitárias. Uma concentração maior de indivíduos distribuídos num pequeno número de espécies também foi encontrada por Lima et al. (1994), Milano (1994) e Silva et al. (2006), mas, em nenhum desses casos com uma predominância tão grande como a encontrada neste trabalho.

Além disso, a relatos de que o Fícus benjamina é prejudicial à estrutura viária da cidade, sendo observados danos a calçadas, calçamento e conflitos com as redes aéreas, embora tais observações não tenham sido detalhadas neste estudo. Santana e Santos (1999) comentaram que o gênero Ficus é causador de problemas como elemento de arborização no Campus da Universidade.

Após o Ficus, a espécie que obteve o maior número de indivíduos amostrados foi a Cassia seamea (25,94\%), árvore bastante comum na arborização urbana na região Nordeste. Resultados semelhantes foram observados por MELO et al. (2007).

Os parâmetros fitossanidade, afastamento predial, situação das copas quanto à fiação, problemas ocasionados pelas raízes, largura do passeio e diâmetro das árvores, escolhidos com vistas a indicar quais as condições da arborização dos bairros Santa Rosa, Jardim Rogério e Santo Antônio, encontram-se na Figura 3.

Ao analisar a fitosanidade dos indivíduos inventariados (Figura 3A), observa-se nos bairros Santa Rosa e Santo Antônio que todas as árvores foram classificadas como de estado bom a regular. Para nenhum dos bairros foi registradas árvores mortas ou em fases finais irreversíveis. No entanto, no Jardim Rogério, foram registrados que 15,63\% das árvores com baixo grau de sanidade, que é um percentual bastante elevado. Quanto à distância das árvores até os imóveis (Figura 3B), o bairro Santa Rosa obteve os melhores resultados. Já os outros dois bairros, obtiverem percentuais superiores a $10 \%$ de árvores que tocavam os imóveis não apresentando afastamento algum. 

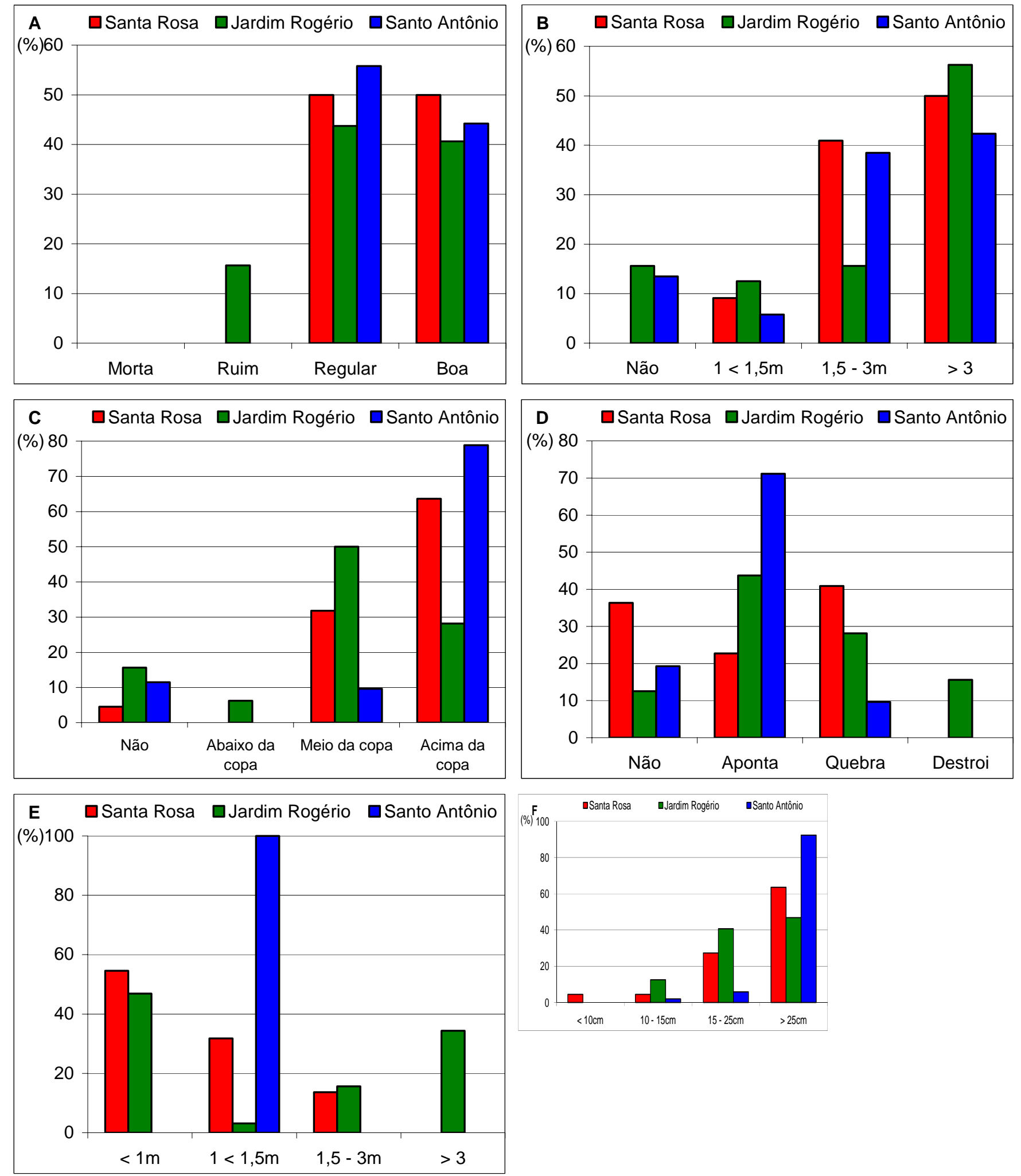

Figura 3. Aspecto da arborização nos bairro Santa Rosa, Jardim Rogério e Santo Antônio, quanto a(o): fitossanidade (A); afastamento das árvores aos imóveis (B); situação das copas quanto à fiação (C); problemas ocasionados pelas raízes (D); largura do passeio (E); e diâmetro das árvores (F). 
A situação das copas quanto à fiação (Figura $3 C$ ) foi outro parâmetro que demonstrou resultados indesejáveis para uma arborização urbana, principalmente para o bairro Jardim Rogério, onde cerca de 50\% das árvores que compõe sua arborização, apresentavam copas incidindo na fiação aérea. Para o bairro Santa Rosa este valor foi de aproximadamente $32 \%$, e para o Santo Antônio chegou a quase 10\%. Deve ser ressaltado que a alta porcentagem de copas incidindo na fiação elétrica, pode ocasionar problemas futuramente, como queda de postes e curtos-circuitos. Para Melo et al. (2006), plantio de árvores nas cidades deve ser compatibilizado com a fiação aérea existente na malha urbana. CEMIG (2001), também destaca que plantios sob fiação devem ser feitos com árvores de pequeno porte em posição alternada com a arborização do outro lado da rua.

Problemas ocasionados pelas raízes das árvores foram observados para todas as espécies (Figura 3D), mas apenas no Jardim Rogério esses problemas foram tão graves a ponto de destruírem as calçadas em quase 16\% dos casos. Em todos os bairros, foram amostrados indivíduos que quebravam os passeios, sendo a maior incidência no bairro Santa Rosa. O bairro Santo Antônio, obteve os melhores resultados quando comparado aos demais, apresentou mais de $70 \%$ dos indivíduos com raízes apontando, o que poderá acarreta um grande volume de problemas no futuro com o crescimento das árvores.

A distribuição das larguras dos passeios (Figura 3E) foram bastante heterogêneas nos bairros Santa Rosa e Jardim Rogério, já para o bairro Santo Antônio, em todos os casos observados as calçadas apresentavam espaços que variaram ente 1,00 e 1,50m, o que é considerado um espaço curto para passeios (CEMIG, 2001).

O diâmetro das árvores (Figura 3E) nos mostra os diferentes perfis das populações arbóreas. Observa-se para o bairro Santo Antônio, que mais de 92\% dos indivíduos apresentaram diâmetro superior a $25 \mathrm{~cm}$, o que representa uma arborização composta maciçamente por árvores adultas. Já para os demais bairros, foram observados percentuais consideráveis de árvores ainda em desenvolvimento, com diâmetros entre 15 a $25 \mathrm{~cm}$ e até inferiores a $15 \mathrm{~cm}$.

Boa parte das árvores avaliadas necessitava de algum tipo de poda, principalmente a poda leve, também conhecida como poda de formação ou de limpeza. No entanto, no bairro Santo Antônio mais de $45 \%$ dos indivíduos necessitavam de uma poda drástica ou pesada. As necessidades de podas a serem feitas pelo gestor público, podem ser evitadas quando moradores cuidam da arborização de seus próprios bairros. Tal fato foi evidenciado por Melo et al. (2007) em estudos realizados na cidade Patos-PB, onde constataram que quase $68 \%$ das árvores não necessitavam de podas devido a cuidados tomados pelos moradores do bairro. 


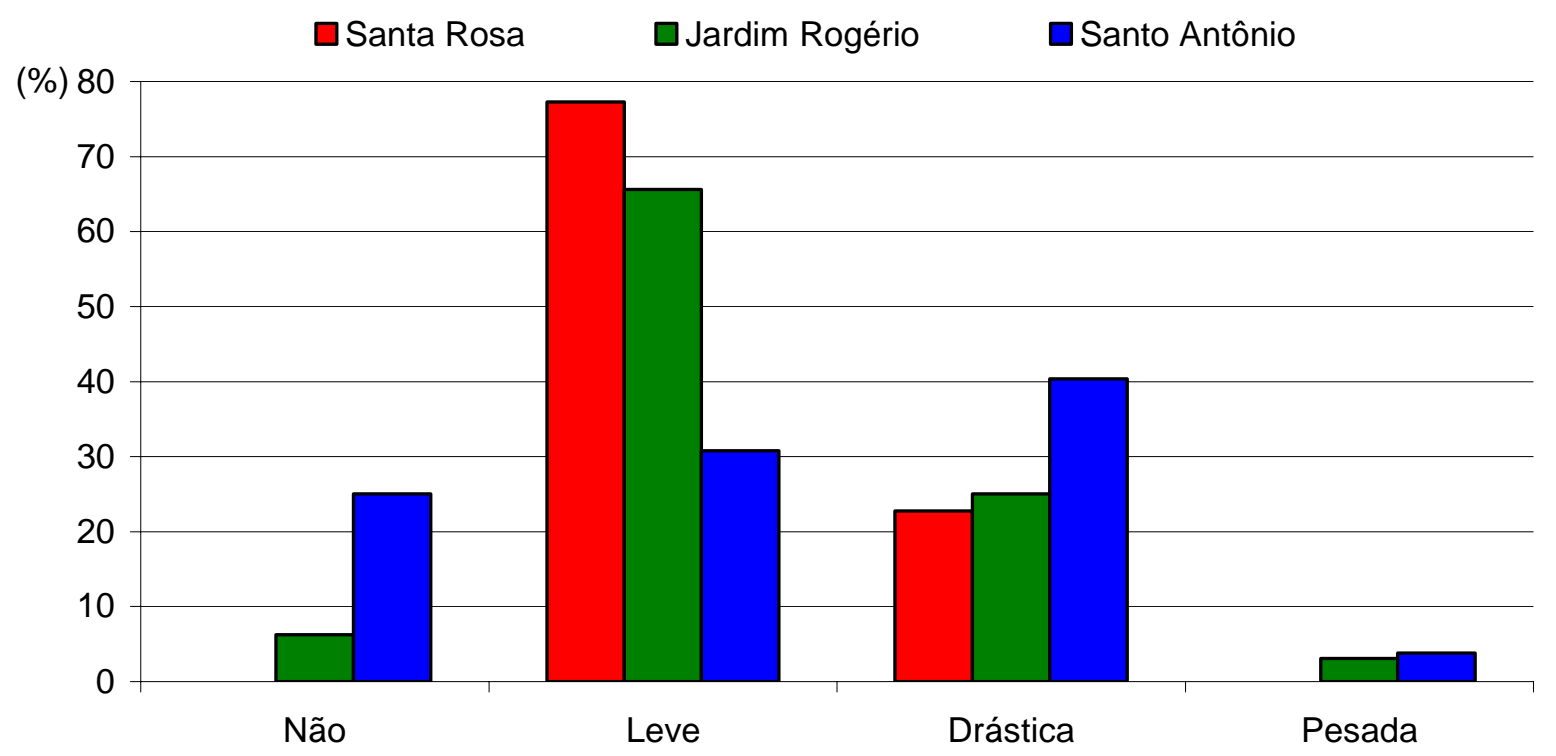

Figura 4. Situação da arborização quanto à necessidade de poda nas árvores.

$\mathrm{Na}$ Figura 5 encontram-se as informações de altura total $(\mathrm{Ht})$ e altura da primeira bifurcação $(\mathrm{Hb})$ das árvores em diferentes classes. A classe "0" equivale a árvores de 0-5m de $\mathrm{Ht}$ e menor que $1 \mathrm{~m}$ de $\mathrm{Hb}$, a classe "1" de 5-10 m de $\mathrm{Ht}$ e de 1-1,5 m de $\mathrm{Hb}$, a classe "2" de 10-15 $\mathrm{m}$ de $\mathrm{Ht}$ e de 1,5-2 $\mathrm{m}$ de $\mathrm{Hb}$, e a por fim a classe " 3 " refere-se a árvores maiores que $15 \mathrm{~m}$ de $\mathrm{Ht}$ e maiores que $2 \mathrm{~m}$ de $\mathrm{Hb}$.

$\mathrm{Na}$ análise da altura total das árvores inventariadas (Figura 5) é confirmada suposta afirmação feita na discussão da Figura 3E, ao observar que no bairro Jardim Rogério nenhuma das árvores amostradas obtiveram altura inferior a $5 \mathrm{~m}$, o que indica que o bairro é composto exclusivamente por indivíduos adultos de médio a grande porte. Os demais bairros apresentaram índices que variaram de 23 a 35\% de indivíduos inferiores a $5 \mathrm{~m}$, o que indica que estes ainda encontram-se com um percentual significativo de árvores jovens. Todavia, o bairro Santa Rosa foi o que demonstrou o maior número de indivíduos com altura superior a $15 \mathrm{~m}$ (45,45\%). Estudos realizados por Rocha et al. (2004) em dois bairros de Nova Iguaçu, no Rio de Janeiro, foram observados que cerca $64 \%$ e $51 \%$ das árvores de cada bairro apresentavam altura inferior à $6 \mathrm{~m}$ e cerca de 10\% e 18\% das árvores tinham altura superior a $8,8 \mathrm{~m}$.

Quanto à altura da primeira bifurcação (ainda na Figura 5), que pode vir a ocasionar problemas para pedestres quando a copa encontra-se voltada para o passeio, ou para meio de transportes quando esta encontra-se voltada para a rua, foi observado apenas para o bairro Santo Antônio, um baixo número de árvores (2\%) com bifurcação abaixo de $1 \mathrm{~m}$. Para os outros dois bairros este índice foi de $50 \%$. Tal resultado sugere que seja realizada uma melhor condução das árvores urbanas, principalmente naquelas que ainda encontram-se em 
estágio inicial de desenvolvimento, para que estas não venham a possuir problemas semelhantes no futuro.

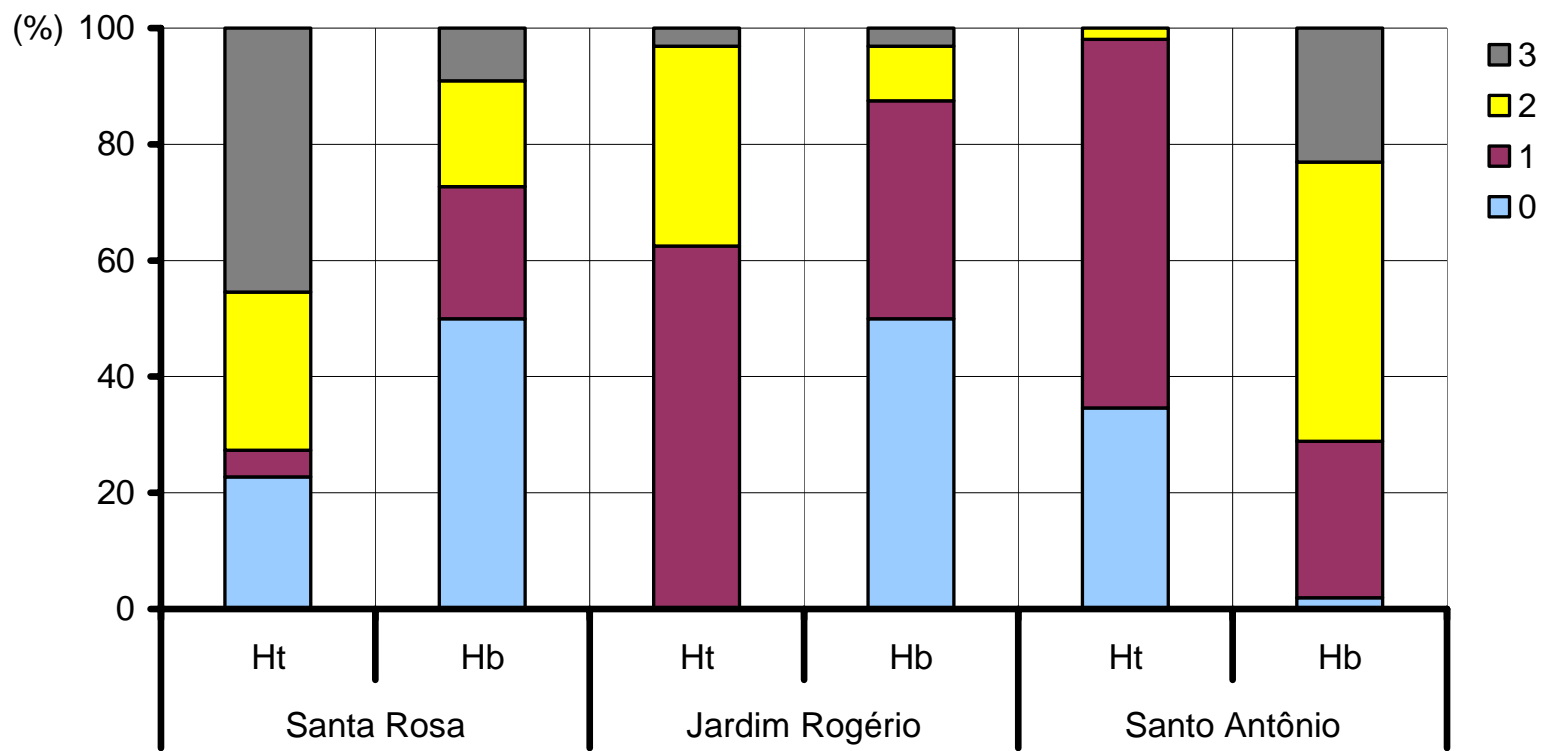

Figura 5. Altura total $(\mathrm{Ht})$ e altura da primeira bifurcação $(\mathrm{Hb})$ das árvores inventariadas.

$\mathrm{Na}$ avaliação da situação das copas das árvores (Figura 6), as informações foram divididas nas seguintes classes: quanto aos avanços da copa longitudinal e da copa para as casas, "0" > 1 copa, "1" < 1 copa, "2" toque e "3" entrelaça; quanto ao avanço para a rua, "0" não há avanço, "1" < 0,50 m, "2" 0,50-1,00 m e "3" > 1,00 m.

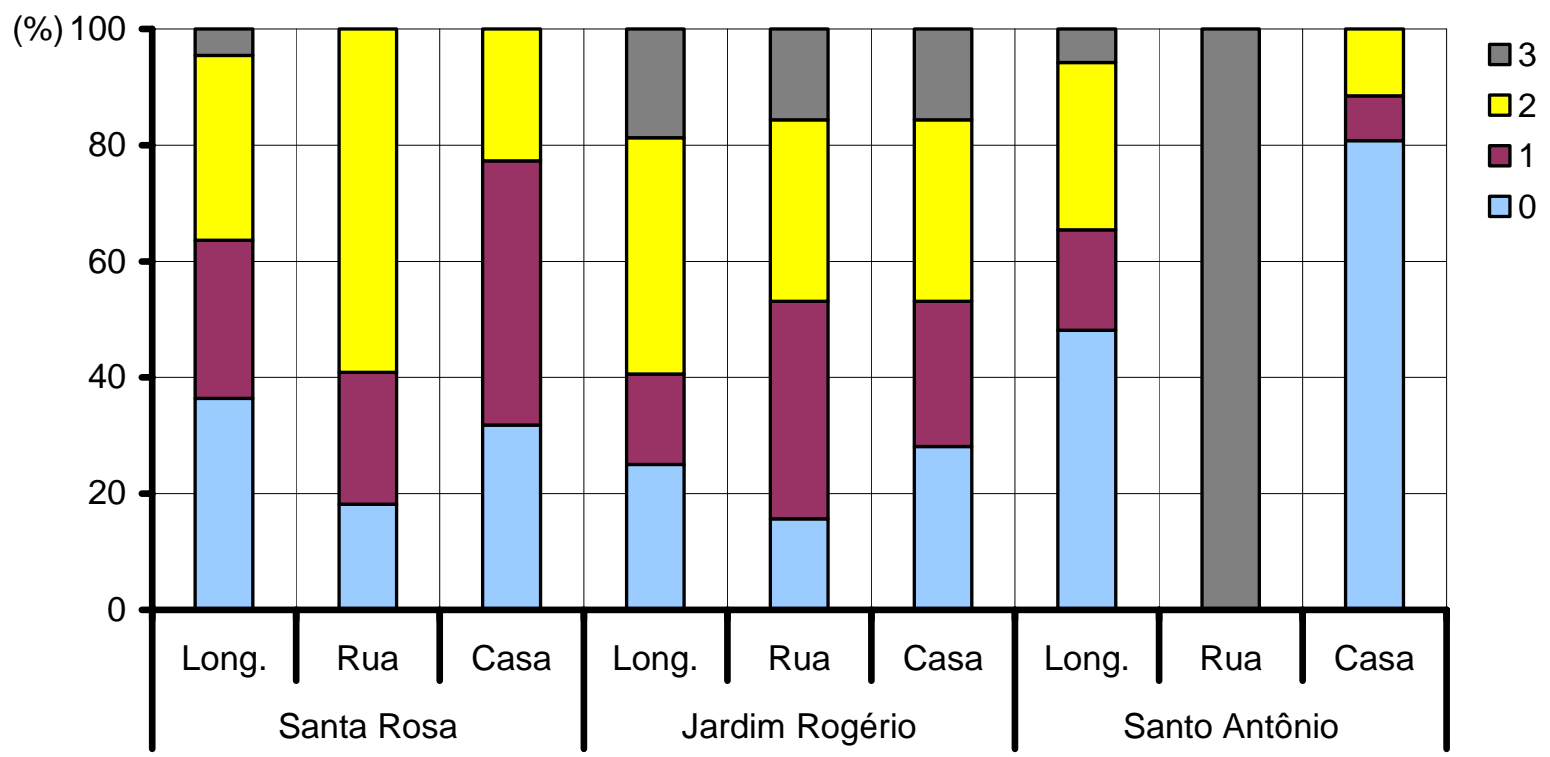

Figura 6. Situação das copas quanto ao avanço longitudinal entre elas, avanço para as ruas e para as casas. 
Para o avanço longitudinal e avanço para as casas, que nada mais é do que a distância longitudinal entre as copas das árvores e a distância das copas das árvores aos imóveis, os bairros Santa Rosa e Santo Antônio obtiveram bons resultados, sendo poucos os casos das árvores se tocarem ou tocarem as casas, e menores os casos de entrelaçamentos. No bairro Jardim Rogério foram observados 19 e 16\%, respectivamente, de copas entrelaçadas entre elas e entre os imóveis. Para copas que apenas se tocavam estes índices foram aproximadamente de 41 e 31\%. Já o avanço das copas para rua foi observado para todas as árvores inventariadas no bairro Santo Antônio, e ocorreu em menor escala nos demais bairros avaliados.

\section{CONCLUSÕES}

Por meio da análise das informações obtidas, pode-se concluir que:

- Os bairros demonstraram grandes variações entre os parâmetros analisados, o que dificulta afirmar qual bairro apresentou as melhores condições em sua arborização. No entanto, o maior número de problemas foi encontrado nas ruas do bairro Jardim Rogério.

- O bairro mais arborizado dentre os avaliados foi o Santo Antônio, que obteve aproximadamente $49 \%$ de todos os indivíduos amostrados.

- Para todos os bairros houve uma baixa diversidade de espécies, com a prevalência de uma única espécie, o Fícus benjamina.

- Os resultados apontam para uma necessidade de melhor planejamento na implantação da arborização nos bairros, assim como, um acompanhamento para manutenção, recuperação ou melhorias na arborização já existente.

\section{REFERÊNCIAS BIBLIOGRÁFICAS}

CEMIG - COMPANHIA ENERGÉTICA DE MINAS GERAIS. Manual de arborização. Belo Horizonte: Superintendência do Meio Ambiente/CEMIG, 2001. 40p.

GONÇALVES, W. Florestas urbanas. Ação ambiental, Ano II, n.9, p.17-19, 2000.

GRAZIANO, T. T. Viveiros Municipais. Departamento de Horticultura - FCAVJ - UNESP. Notas de Aula, 1994.

GREY, G. W., DENEKE, F. J. Urban forestry. New York, John Wiley \& Sons, 1986. 279 p. INSTITUTO BRASILEIRO DE GEOGRAFIA E ESTATÍSTICA - IBGE. 2008. Mapas interativos. Disponível em: < http://www.ibge.gov.br/mapas/>. Acesso em outubro de 2008. LIMA, A. M. L. P., COUTO, H. T. Z., ROXO, J. L. C. Análise de espécies mais freqüentes da arborização viária, na zona urbana central do município de Piracicaba-SP. In: CONGRESSO 
BRASILEIRO DE ARBORIZAÇÃO URBANA, 2, 1994, São Luis. Anais... São Luís, 1994. p.555-573.

MELO, R.R.; FILHO, J.A.; RODOLFO JÚNIOR, F. Diagnóstico qualitativo e quantitativo da arborização urbana no bairro Bivar Olinto, Patos, Paraíba. Revista da Sociedade Brasileira de Arborização Urbana, v.2, n.1, 2007, p.64-78.

MILANO, M.; DALCIN, E. Arborização de vias públicas. Rio de Janeiro: LIGHT, 2000. $226 \mathrm{p}$.

MILANO, M.S. Métodos de amostragem para avaliação de ruas. In: Congresso Brasileiro sobre Arborização Urbana, 2, São Luiz, 1994. Anais... São Luiz: SBAU, 1994. p.163-168.

MILLER, W. R. Urban forestry - planning and managing urban greenspaces. 2.ed. New Jersey: Prentice-Hall, 1997. 502 p.

MINISTÉRIO DE MINAS E ENERGIA - MME. Projeto cadastro de fontes de abastecimento por água subterrânea no Estado da Paraíba: diagnóstico do município de Pombal. MME: Recife, 2005. 23p.

PARAÍBA. Atlas geográfico do Estado da Paraíba. Secretaria de Educação, Governo do Estado da Paraíba: Universidade Federal da Paraíba. 1985.

ROCHA, R.T.; LELES, P.S.S.; OLIVEIRA NETO, S. Arborização de vias públicas em Nova Iguaçu, RJ: o caso dos bairros rancho novo e centro. Revista Árvore, Viçosa, MG, v.28, n.4, p.599-607, 2004

SANCHOTENE, M. do C.C. Desenvolvimento e perspectivas da arborização urbana no Brasil. In: Congresso Brasileiro de Arborização Urbana, 2, 1994. São Luís-MA. Anais... São Luís, Sociedade Brasileira de Arborização Urbana; 1994.

SANTANA, J.R.F.; SANTOS, G.M.M. Arborização do campus da UEFS: exemplo a ser seguido ou um grande equívoco? Sitientibus, n.20, p.103-107, 1999.

SILVA JÚNIOR, O. A. B. MÔNICO, M. O. M. Arborização em Harmonia com a Infra-estrutura Urbana. In: $1^{\text {a }}$ Semana de Meio Ambiente. Prefeitura Municipal de Guarulhos: Secretaria de Meio Ambiente, 1994.

SILVA, A. G. Arborização urbana em cidades de pequeno porte: avaliação quantitativa e qualitativa. 2000. 150f. Dissertação (Mestrado em Ciências Florestais), Universidade Federal de Viçosa, Viçosa, 2000.

SILVA, A.G.; GONÇALVES, W.; LEITE, H.G.; SANTOS E. comparação de três métodos de obtenção de dados para avaliação quali-quantitativa da arborização viária, em Belo Horizonte-MG. Revista da Sociedade Brasileira de Arborização Urbana, v.1, n.1, 2006, p.31-44. 
TAKAHASHI, L. Y. Arborização urbana: inventário. In: CONGRESSO BRASILEIRO DE ARBORIZAÇÃO URBANA, 2., 1994, São Luís. Anais... São Luís: Sociedade Brasileira de Arborização Urbana, 1994. p.193-200.

VOLPE-FILIK, A.; SILVA, L.F.; LIMA, A.M.P. avaliação da arborização de ruas do bairro são dimas na cidade de piracicaba-sp através de parâmetros qualitativos. Revista da Sociedade Brasileira de Arborização urbana, v.2, n.1, 2007, 10p. 